\title{
Demonología en la apocalíptica y Qumrán ${ }^{I}$
}

\author{
César Carbullanca \\ UNIVERSIDAD CATÓLICA DEL MAULE \\ carbullanca@yahoo.com
}

Resumen: Las diferencias y semejanzas en la demonología de los escritos enóquicos y de Qumrán ha sido un tema permanente en la actual discusión de la apocalíptica. El artículo estudia estos cambios o desplazamientos en la tradición enóquica y en los textos de Qumrán, durante el periodo helenista en relación a la demonología y específicamente con la impureza, la teodicea y la escatología presente en los diversos escritos durante este periodo. Si bien el núcleo de esta nueva fase lo representa el mito de los Vigilantes, el cual representa la base ideológica presente en diversos textos apocalípticos y en Qumrán, dicho núcleo no puede ser considerado un sistema demonológico coherente que relaciona la existencia de demonios, impureza y diversas enfermedades las cuales son conjugadas en diversa manera en vista de reflexionar la justicia escatológica.

Palabras clave: Demonología, Enoch, escatología, apocalíptica, Qumrán

Abstract: Differences and similarities in the demonology of enoquic and Qumran writings has been a permanent topic in the current discussion of the apocalyptic. The article examines these changes or shifts in the enoquic tradition and the Qumran texts, during the Hellenistic period in relation to demonology and specifically to impurity, theodicy and this eschatology in the various written during this period. While the core of this new phase represents the myth of the Watchers, which represents the present ideological basis in various apocalyptic texts at Qumran; this core can not be considered a coherent system that relates demonological the existence of demons, impurity and various diseases which are combined in different ways to reflect the eschatological view of justice.

Keywords: demonology, Enoch, eschatology, apocalyptic, Qumrán

1 Artículo producto de la inVestigación Fondecyt 1120029 


\section{EL PROBLEMA}

Las diferencias y semejanzas en la demonología de los escritos enóquicos y de Qumrán han sido un tema permanente en la actual discusión sobre apocalíptica. Por un lado, en diversos puntos señalados por Gabriele Boccaccini y otros autores se sostiene existe una continuidad ${ }^{2}$, por el otro, a juicio de David Suter en la demonología presente en la literatura enóquica se debe hablar de "discontinuidades" y hasta de un "dramático quiebre" y de la misma manera Paolo Sacchi señala que existen "mutaciones radicales que caracterizaron la historia henoquita" ${ }^{4}$. Por tanto, la continuidad la estudiaremos fundamentalmente comprobando el impacto y presencia de la demonología que representa el mito de los Vigilantes en los diferentes escritos. A su vez, estudiaremos los cambios o desplazamientos en la tradición enoquica y en los textos de Qumrán, durante el periodo helenista en relación a la demonología y específicamente a tres cuestiones: la pureza, la teodicea y la escatología histórica. En este periodo aparecen diversos sistemas demonológicos que a nuestro parecer por medio de la demonología desarrollan ideas innovadoras en las tres cuestiones mencionadas; y en cada una de estas tres áreas, como estudiaremos, la apocalíptica produce cambios más o menos radicales en el pensamiento judío, de una pureza ritual se pasa a otro concepto de pureza radical; de interés por el reinado nacional se pasa a la cuestión de la justicia divina en el mundo y desde una perspectiva trascendente del mito de los Vigilantes se pasa a formulaciones histórico-escatológicas. La investigación de manera inevitable presenta un cierto carácter panorámico, estudiando algunas características y la relación que establece la demonología con la impureza, la teodicea y la escatología histórica presente en los varios escritos durante este periodo. Para esto haremos un estudio diacrónico de diversos textos judíos postexílicos como 1 Enoch y Jubileos y finalmente algunos textos de la literatura de Qumrán.

2 Cf. G. Boccaccini, Oltre l'ipotesi essenica.Lo scisma tra Qumran e il giudaismo enochico (Morcelliana, Brescia 2003), 299 Boccaccini señala que "se gli enochici non erano esseni allora bisognerebbe dire che assomigliavano a loro come gemeli"

3 D. Suter, "Theodicy and the problem of the Intimate Enemy", en G. Boccaccini(ed.)Enoch and Qumran Origins. New Light a Forgotten Connection, (W. Eerdmans. Publishing Company, Grand Rapids 2005) 332.

4 P. SAcchi, Historia del Judaísmo en la época del Segundo Templo (Trotta, Madrid 2004) 359. 


\section{Primeros teXtos apocalípticos}

En el área de la demonología, Israel adoptó creencias y preceptos comunes a otros pueblos como Mesopotamia, Egipto, Babilonia y Grecia. Más específicamente, el periodo postexílico asistimos al ingreso de la demonología de Mesopotamia introducidos en el ámbito de la fe judía según la cual, los demonios son causantes de enfermedades y males de todo tipo.

\section{Identificación entre contaminación e impureza}

El mito de los Vigilantes es narrado en el Libro de los Vigilantes 6, 1-8, 4. En este relato el protagonista no es Enoch sino al parecer Noé (10, 2). Enoch es introducido en el relato a partir de capítulo 12, la sección de los capítulos 1-5 son posteriores, a juzgar por el uso del pasaje la Escritura que hace en 5, 7. Una de las perspectivas que es necesario estudiar es la identificación entre pecado y contaminación que desarrolla el mito de los Vigilantes. Al respecto, Ida Fröhlich sostiene que "la creencia en demonios es elemento nuclear en comprensión del concepto de impureza ritual" 5 y relaciona el texto de 4Q510-511 con la tradición del mito de los Vigilantes ${ }^{6}$. La LXX traduce el término טמא por $\mu$ íavw (Lev 11, 43). Este verbo ( $\mu$ íav $\omega)$ es usado con frecuencia en el libro del Levítico, para hablar de la contaminación ritual, sin embargo a diferencia del concepto de impureza preexílico, en la primera apocalíptica, la contaminación consiste en una impureza radical que afecta a todas las dimensiones del género humano que ya vemos esbozado en algunos textos b’blicos como Sal 14, 1; 143, 2; Hag 2, 13 al constatar la imposibilidad de la existencia del justo.

En la versión del Libro de los Gigantes, el fragmento encontrado en Qumrán, 4Q203 (4QEnGiants ar) en el fr.9, califica el pecado de Shemyaza como זבל y " זנות "corrupción”. La corrupción o miasma definida por J. P. Vernant como "potencia de contagio", significa la contaminación provocada por el asesinato, pero ya en Ezequiel como en 1 Enoch el concepto es ampliado a la idolatría, inmoralidad

5 I. FrÖHLICH, “Theology and demonology in Qumran texts”, Henoch 32/1(2010) 108.

6 Cf. Fröhlich, "Theology and demonology", 109.

7 J. P. Vernant, Mito e sociedade na Grecia Antiga (Rio de Janeiro 1999) 107-108; FrÖHLICH, “Theology and demonology", 101-129. 
e injusticia ${ }^{8}$. La definición de miasma es colocada en directa relación a la transgresión de los ángeles. En el texto etíope muestra la vinculación entre contaminación y derramamiento de sangre: "los gigantes se volvieron contra ellos y se comían a los hombres" (v.4). "Y comenzaron a pecar con las aves, los animales y reptiles y peces y unos de otros devoraron las carnes y bebieron la sangre". El Salmo 79, 1-4 muestra también esta ampliación del concepto. La destrucción que las naciones pero también la que el propio Israel realiza con sus abominaciones provoca un "miasma", una profanación del Templo; que la ciudad sea reducida a escombros; que los cadáveres sean comidos por las aves y animales, que se derrame sangre en la ciudad y que los cadáveres queden sin enterrar.

\section{La impureza y las dos tradiciones de Shemyaza y Asael}

Autores como P. Sacchi, G. Nickelsburg, P. Hanson, M. Knibb, D. Suter están de acuerdo en hablar de dos tradiciones demonológicas, primera de Shemyaza y la segunda de Asael ${ }^{9}$. La primera está descrita en el mito de los Vigilantes en 1Enoch 6, 1-8, 4; el pasaje de 9, 6-11 es una mezcla de ambas tradiciones; mientras que 15, 2-12 pertenece a la tradición de Shemyaza y lo mismo el pasaje de 19, 1. Esta tradición sostiene que el pecado de Kilayim o como lo define L. Doering "precepto de las especies diversas" ${ }^{10}$ es aplicado no solo al ámbito de las semillas y animales sino a toda la creación; mostrando que la profanación radica en una mezcla transgénica de especies diversas o relaciones híbridas ocurrida entre: semillas, vegetales, animales, hombres y seres divinos como los ángeles (Lev 19, 19; Deut 22, 9-11). Los gigantes y espíritus malos son comprendidos a la luz de la impureza levítica, lo cual está claramente definida en el v. 8: "Los espíritus malos proceden de sus cuerpos, porque han

$8 \quad$ Ez 5, 11; Ez 22, 3; 23, 30; Jer 3, 2; Is 43, 28.

9 P. SACCHI, "Riflessioni sull' essena dellàpocalittica: Peccato d' origine e liberta 'dell "uomo", Henoch vol V (1983) 31-61; G. Nickelsburg, 1 Enoch Vol. I: Commentary on the Book of 1 Enoch Chapters 1-36, 81-88 (Hermeneia-Critical and Historical Commentary on the Bible) (Fortress press, Minneapolis 2001), 170; P. D Hanson., "Rebellion in Heaven, Asael, and Euhemeristic Heroes in 1 Enoch 6-11", JBL 96/2 (1977) 195-233; M. KNiBB, "Interpreting the Book of Enoch: reflections on recently published commentary", JSJ XXXIII/4(2002)448; D. SuTER, "Revisting "Fallen angel, fallen priest"”, Henoch XXIV (2002)137-142.

10 L. Doering, "Purity and Impurity in the Book of Jubilees", en G. Boccaccini And G. IBBA (eds.), Enoch and the Mosaic Torah.The evidence of Jubilees (W. Eerdmans Publishing, Grand Rapid 2009) 261-275 
nacido de humanos y de los santos Vigilantes". La segunda tradición, de Asael presente en 1 Enoch 8, 1-3; 9, 6, es calificada de diversa manera por los especialistas. A juicio de Nickelsburg "una interpolación" ${ }^{11}$ y que Paolo Sacchi lo llama "bloque errático"12, que reaparece en el Libro de las Parábolas (1Enoch 69, 9-11). Paul Hanson considera a esta como "una elaboración interpretativa que desarrolla orgánicamente la narrativa de Semihazah"13, sosteniendo en diversos pasajes del mito de los Vigilantes las dimensiones mitológicas del relato bíblico de Génesis y Levítico. En relación a Azazel de Lev 16 sostiene que a propósito de 1Enoch 10, 8b: "escribe sobre él todo pecado", habría una "identificación de Azazel con el celeste Asael, este intérprete subrayó la dimensión mitológica del tema del Yom Quippur"14. En esta segunda tradición, los ángeles caídos enseñan a las mujeres misterios divinos: "fabricar armas", "corazas, "lanzas", "la medicina mágica, los encantamientos, los tallos de las raíces y el conocimiento de la plantas" $(7,1)$. Esta descripción coincide por un lado, con áreas del conocimiento que muestra Sab 7, 17-20. Conocimientos de metalurgia, botánica, zoología y astronomía que comienzan a ser estructurados en el mundo circundante a Israel. Estas descripciones del pecado de Asael contrasta con lo que enseñará Jub 3, 15, y más aún en las Parábolas de Enoch $(69,9)$ se indicará que es debido a la escritura que entró el pecado en el mundo: "a causa de ese saber suyo perecen y por esta fuerza son consumidos". Por un lado, es preciso constatar la diversidad de opiniones de los especialistas y por el otro, es necesario insistir que el relato de 1Enoch 6-11 no es independiente y está orientado a una problemática más amplia que presenta el libro en torno al juicio de Dios. De acuerdo con autores como Suter ${ }^{15}$ que sostienen que relato de 1Enoch 6-11 estaría interesado en una polémica con el sacerdocio de Jerusalén, consideramos que la identificación de contaminación y pecado significa una deslegitimación radical del sacrificio y sacerdocio presentado en el Levítico y que veremos acentuada en la neumatología de Qumrán.

1 G. Nickelsburg, "Apocalyptic and Myth in 1Enoch 6-11”, JBL 96/3(1977) 386.

12 P. SACCHI, Historia del Judaísmo en la época del Segundo Templo (Trotta: Madrid 2004) 359.

13 Hanson, "Rebellion", 220.

14 Hanson, "Rebellion", 221; la crítica de la propuesta de Hanson en Nickelsburg, "Apocalyptic and Myth", 41-43.

15 Cf. Suter, "Revisting", 137-142. 
3. La teodicea del relato de los Vigilantes

En opinión de Paolo Sacchi el problema de la teodicea no existe en la primera demonología presente en el Libro de los Vigilantes. Ciertamente tanto P. Sacchi y de G. Boccaccini ${ }^{16}$ atienden poco a la relación entre la demonología y la teodicea. Otros autores como, Nickelsburg, Hanson y Elliot ${ }^{17}$ atienden a esta perspectiva, pues muestra que la continuidad entre la literatura enóquica y Qumrán no radica simplemente en las sanaciones y exorcismos sino en algo más profundo, el interés por la teodicea. Para P. Sacchi la pregunta por la teodicea surge alrededor del 160 a.C. recién con el Libro de los Sueños ${ }^{18}$, sin embargo, ya en el mito de los Vigilantes la oración de ángeles, patriarcas y profetas, como p.e. la de 1 Enoch 9, 11; 10, 10-13 ${ }^{19}$, aparece el problema de la teodicea expresado claramente. En el texto de 1Enoch 9, 1-11 los ángeles preguntan a Dios:

"tú has visto lo que ha hecho Asael al enseñar toda clase de iniquidades... Semyaza a quién tú has dado poder para regir a los que están junto con él, ha enseñado conjuros... ahora pues, claman las almas de los que han muerto... tú sabes todo antes de que suceda; tú sabes estas cosas y las permites sin decirnos nada: ¿qué debemos hacer con ellos a causa de esto?".

Además, a juicio de $\mathrm{P}$. Hanson la oración de los ángeles representa a los miembros de un grupo protagonista que están sufriendo la opresión ${ }^{20}$.

\section{Demonología fuera de la historia}

Si bien en el Libro de los Vigilantes "los humildes" son mencionados ( 5 , $7 ; 10,17 ; 25,4)$ sin embargo los protagonistas son los ángeles debido a la perspectiva metahistórica del relato, en cambio en el Libro de los Sueños y sobre todo en la Epistola de Enoch debido a su perspectiva intrahistórica los protagonistas son los justos $(97,5)$ quienes son identificados con los pobres y son ellos los que claman a Dios.

6 Boccaccini, Oltre l'ipotesi essenica, 295-297.

17 Cf. Nickelsburg, "Apocalyptic and Myth", 404; M. Elliot, "Origins and functions of the Wachters theodicy", Henoch vol. XXIV (202), 63-75.

18 SACCHI, Historia, 370. También nota a pie de página 14.

19 O. Bocher, , "daimo, nion”, en Horst Balz; Gerd Schneider (eds.) Diccionario exegético del Nuevo Testamento (Sígueme, Salamanca 2001) 818.

20 Cf. Hanson, "Rebellion", 219 
El mito de los Vigilantes desarrolla la pregunta por la justicia en términos cósmico-trascendentes en cambio en la apocalíptica posterior, será planteada en términos históricos: profetas, patriarcas y justos como Job, Esdras o los justos de los salmos será quienes pregunten "¿Por qué nosotros sufrimos?”, "¿hasta cuándo ocultas tu rostro?” (Sal 131, 1; Hab 1, 1-2; 1QpHab col. I, 1; 4Ez 4, 12). Finalmente, en el relato de los Vigilantes hay una reflexión mítica que integra motivos bíblicos que tienen como tema la justicia divina como por ejemplo, la sangre de Abel o de atar a Asael, pero que aún carece de un marco histórico salvífico; aun así, el paralelo de Gén 4, 10 y 1 Enoch 8, 4 evidencia la oración de los ángeles como medio para preguntar por la justicia de Dios en el mundo. Si es efectiva la perspectiva paradigmática del relato, como lo sostienen Nickelsburg y Hanson, el paralelo de 1 Enoch 8, 4 es significativo pues establece la relación entre la sangre de Abel que clama al cielo y la oración de los hombres en 1Enoch 8, 4 "los hombres clamaron en su ruina y llegó su voz al cielo"; y también en 1Enoch 9, 9: "toda la tierra está llena de sangre e iniquidad. Ahora pues, claman las almas de los que han muerto, se quejan hasta las mismas puertas del cielo". Como también lo hace notar M. J. Davidson ${ }^{21}$ en otros textos posteriores, el tema de la oración del pueblo, de Enoch, de los ángeles y patriarcas guarda relación con el tema de la teodicea.

\section{Historia y escatología en el Libro de los Gigantes y Daniel}

Según la opinión de Józef Milik ${ }^{22}$, la fecha de composición de EnGiant pertenece a finales del siglo II a. C., circunscribiéndolo entre la redacción de Jubileos y la de 4QEnGiantsb, copiado en la primera mitad del primer siglo a. C.; según Milik este espacio de tiempo debe ser restringido si la cita de CD 2, 18 pertenece al libro de los Gigantes. Los textos de Dn 9-10b y 4Q530 presentan una cercanía terminológica innegable; además de la mención de los tronos y los mil que están de pie ante los tronos, el texto de Dn 7, 16 usa el término pesher, lo mismo que el texto

21 Cf. J. Davidson, Angels at Qumran. A comparative Study of 1 Enoch 1-36, 72-108 and Sectarian Writing from Qumran, (JSOT, Sheffield Press, Sheffield 1992) 56. El contraste entre el sufrimiento de Israel y la suerte de Babilonia: "¿Por qué tú destruyes a tu pueblo y eres misericordioso con tus enemigos? Es que Babilonia es algo mejor que Sión?” (4Esd 3, 30).

${ }^{22}$ Cf. J. Milik, The Books of Enoch. Aramaic Fragments of Qumran cave 4 (Clarendon Press, Oxford, 1970) 58. 
de 4Q530 col. II, 23 y col. III, 10; una primera cuestión que surge es, si la dependencia es de Dn 7 de EnGiants o viceversa; según la opinión de Milik y VanderKam ${ }^{23}$, la fecha de composición de EnGiant pertenece a finales del siglo II a. C., circunscribiéndolo entre la redacción de Jubileos y la de 4QEnGiantsb, copiado en la primera mitad del primer siglo a. C.; según Milik este espacio de tiempo debe ser restringido si la cita de CD col. II, 18 pertenece al Libro de los Gigantes. Según algunos autores, el relato de Dn 7 acontece posteriormente al 150 a. C., y para J. Collins habría sido escrito alrededor de diciembre de 167 a. C. ${ }^{24}$ En todo esto nos parece que la opinión de F. García Martínez ilumina nuestro quehacer:

"[...] lo más interesante, sin embargo es que uno de estos manuscritos (4QEna) se debe datar a comienzos del siglo II a.C., lo que nos obliga a admitir una fecha de composición del original en el siglo III a.C., esto no sólo hace del Libro de los Vigilantes el apocalipsis más antiguo, muy anterior a Daniel, sino que desconecta los orígenes de la apocalíptica de la crisis provocada por la helenización de Palestina y por la revuelta macabea" 25 .

De acuerdo a estos datos tenemos que la tradición presente en 4QEnGiants $^{\mathrm{b}}$ conserva una antigua tradición de 1 Enoch y transmitida posteriormente en Dn 7, 9-11 acerca del trono de Dios y sus ministros. Esta también es la opinión de Stefan Beyerle "la visión del sueño en el libro de los Gigantes representa una más antigua tradición comparada con mucho más elaborada escatología de Dn 7"26.

En el texto de 4Q203 (4QEnGiants ${ }^{\mathrm{a}}$ ar) 4QBook of Giants ${ }^{\mathrm{a}}$ ar, aunque fragmentario, se puede reconocer la tradición del Mito de los Vigilantes, en el fr.7 "luego él ha castigado y no a nosotros sino a Azazel e hizo a él... los hijos de los Vigilantes, los gigantes y ninguno de sus amados será perdonado"; en el fr. 8 menciona a "Shemihazah y a toda su compañía"; "9 por tu prostitución en la tierra. Esto ocurrirá para ti... la

${ }^{23}$ Cf. Milik, The Books of Enoch... , 58; J. VAnderkam, From Revelation to Canon. Studies in the Hebrew Bible in Second Temple Literature, (J. Brill, Leiden 2000), 308.

24 Cf. J. J Colurns, Daniel, A Commentary on the Book of Daniel, (Fortress press, Minneapolis 1993) 81.

25 F. García Martínez, Literatura Judía intertestamentaria (Estella, Navarra 1996) 85.

26 S. BeyerLe, “One like a Son of man": Innuendoes of a Heavenly Individual", en G. Boccaccini (ed.) Enoch and Qumran Origins. New Light on a Forgotten Connection (W. Eerdmanns, Grand Rapids 2005) 57. 
corrupción con la cual has corrompido a ésta". También en el texto de 4Q531 fr. 51 [...] "ellos se profanaron a ellos mismos [...] 2 [...] los gigantes y los nefilim" 4Q532 fr.2, "9 [...] ellos cometieron una gran injusticia sobre la tierra".

Una diferencia notable radica en el hecho que en el texto de 4QEnGiants $^{\mathrm{b}}$ col. II, 17 conserva una antigua tradición según la cual uno de los Vigilantes llamado Ohyah tiene un sueño en el cual la Gloria de Dios desciende sobre la tierra para realizar el juicio. Ideas escatológicas similares encontramos en Joel 3, 1-5 y Mal 4, 1. El autor de Daniel adaptó ideas sobre el arribo del eschaton en Dn 7, 9-15 añadiendo el v.13 "un Hijo de hombre"; así también en Jubileos señala que es Enoch quien es enviado a la tierra, como dice en Jub 1, 12; 4, 18.30 "éste fue el primero que escribió un testimonio y testificó contra los hijos de los hombres a través de las generaciones". Esta tradición prequmrámica aparece en el texto de 4Q201 4QEnoch ar col. I, 1-3 de Qumrán que es una copia de 1 Enoch 1, 1-6 pero los vv. 4-6 no continúa la introducción de 1Enoch, sino más bien corresponden a la tradición del texto del Libro de los Gigantes:

"[...] ahora yo hablo sobre los elegidos, concerniente a ellos yo declaro mi oráculo diciendo: 5[...] El Santo saldrá de su morada y el eterno Dios descenderá sobre la tierra y caminará al monte Sinaí y aparecerá con su gran ejército y aparecerá en la batalla de sus fuerzas desde las alturas de los cielos".

La imagen del descenso de la Gloria a la tierra y la caminata al monte Sinaí es una metáfora militar que muestra el interés del redactor por oponer al descenso de los Vigilantes sobre el Hermón este otro sobre la tierra y el monte Sinaí introduciendo de esta manera el juicio de los ángeles en el curso de la historia de Israel. Este nuevo interés por la historia, se aprecia claramente en el libro de Daniel. En este libro se habla de ángeles Vigilantes $(4,13.23)$ también menciona a Miguel como ángel protector de Israel $(10,13.21 ; 12,1)$; y su contraparte son quizás los príncipes de Persia y Grecia $(10,13 ; 20)$. Daniel no menciona un pecado de los ángeles más bien habla de reinos bestiales y de oposición al pacto santo y al igual que en la segunda visión del Libro de los sueños asume una perspectiva histórica del pecado que desarrolla una metafórica zoomórfica: los cuatro reinos bestiales $(7,3)$ "carnero", "bestia" "macho cabrío" (Dan 8, 3.4). Sobre todo a partir de la profecía de Jeremías 
acerca de las setenta semanas de años que duraría el destierro desarrolla un pesimismo histórico.

\section{NuEVA APOCALÍPTICA}

1. La impureza y el Libro de los sueños

El Libro de los sueños (83-90) conoce el relato de los Vigilantes (84, 4; $86,1-6)$ que es narrado metafóricamente mediante animales. El libro presenta dos secciones bien delimitadas; la primera en 83, 1-84, 6; y la segunda, 85, 1-89, 42. La primera sección menciona la idea de la caída de los ángeles que está descrito 84, 4-6; también aparece en la segunda sección llamada Apocalipsis de la animales, el cual posee una estructura similar al Apocalípsis de las diez semanas (93, 1-17). Esta segunda sección muestra la imagen del pecado de los Vigilantes de acuerdo a una primera caída de una estrella y la posterior caída de otras estrellas (86, 1-3) la cual es diferente del relato del capítulo 6. Sin embargo, el autor conserva la idea del mito de los Vigilantes según la cual toda la historia humana está contaminada desde sus comienzos pero que tendrá una liberación una vez finalizado el juicio de Dios. En este sentido a diferencia del libro de los Jubileos que menciona la petición de Mastema por la décima parte de los demonios, en el Libro de los Sueños, presenta a los Setenta pastores $(89,59-90,42)$. Según este relato, el sufrimiento y el mal de las ovejas es descrito como una desobediencia de los pastores; desobediencia entendida como "exceso": "atiende y mira todo lo que hacen los pastores con esas ovejas, pues harán perecer de ellas a más de las que les he ordenado; anota todo exceso" (1Enoch 89, 61-62). El exceso por cuenta propia es anotado por el escriba, que es distinto de Enoch (v.70). En ambos relatos el sentido es el mismo, se trata de una teodicea mítica que explica los males e injusticia en el curso histórico.

La segunda visión es el relato de la historia de salvación, de acuerdo a un simbología zoomórfica: justos y profetas son descritos como toros blancos. Algunos de ellos, Adán, Set, Noé y Moisés se transforman en hombre (1Enoch 85,$3 ; 89,1.36)$; Vigilantes y gigantes son simbolizados por astros, elefantes, camellos y asnos $(86,4)$ respectivamente. Interesante es que la caída del astro principal y sus seguidores $(86,1.3)$ ocurre posterior al nacimiento de Adán y Eva simbolizados por el toro blanco y la ternera respectivamente; también posterior a Caín y Abel simbolizados 
por el becerro negro y rojo respectivamente. También es posterior al nacimiento de Set simbolizado por un toro blanco. Es posible que el redactor esté siguiendo el relato del Gén 2-5, en cambio la sección de 86, 1-88, 3 sigue el relato de los Vigilantes. A partir del Libro de los sueños encontramos un cambio de perspectiva al introducir una visión degenerativa o pesimista de la historia; se trata de la típica idea apocalíptica de la periodización de la historia que expresa un determinismo que fundamenta el dominio del mal hasta la irrupción del juicio de Dios. En el Libro de los sueños y en Daniel esta periodización está basada en el número siete; en cambio encontramos en Jubileos y 11QMelquisedec que la historia está dividida en diez jubileos. Un aspecto interesante de notar es que los ángeles no luchan ya contra los hombres como raza sino contra el pueblo de los patriarcas, así p.e. Mastema interviene contra Abram y Moisés.

A diferencia del Libro de los Vigilantes en la cual la oración es realizada por los ángeles, en el Libro de los Sueños (83-90) es Enoch, que intercede por los justos $(83,10 ; 84,1-6)$. "Tú sabes, ves y oyes todo, y nada se te oculta... ahora tus ángeles celestiales pecan, y tu cólera permanece sobre la raza humana hasta el gran día del juicio" (v. 4). La oración de Enoch es para que Dios deje un "resto sobre la tierra y no la aniquile toda" (83, 8); "a los justos y rectos mantenlos". Estas diferencias son importantes pues muestra un avance en la perspectiva que asume la teodicea integrando la dimensión histórica como apreciamos en posteriores escritos.

\section{Noé, Abram y José como exorcistas}

La demonología se desarrolla en función de responder a la cuestión de la teodicea. El libro de los Jubileos en primer lugar asume conocimientos médicos y botánicos de tan modo que son ángeles enviados por Dios quienes enseñan a Noé medicamentos (Jub 10, 10). En segundo, lugar, los conocimientos científicos están en función de colocar la demonología dentro de la historia de salvación, así Abram y demás patriarcas serán un antitipo del príncipe Mastema (Jub 18, 10-12). En este sentido, el interés por la teodicea presente en los primeros capítulos de 1 Enoch pasa del ámbito del cosmos al de la historia de Israel. J. van Ruiten subraya "la fuerte semejanza en la forma y contenido" ${ }^{27}$ entre la oración

27 J. van Ruiten, “Abram's Prayer: The coherence of the Pericope in Jubilees 12 :1617, en G. Boccaccini And G. IbBa (eds.)Enoch and the Mosaic Torah. The evidence of Jubilees”(W. Eerdmanns, Grand Rapid 2009), 211-228, 219. 
de Abram, de Noé y Moisés. Las oraciones y bendiciones de ángeles y patriarcas antediluvianos y de la historia de Israel tienen un carácter intercesor y exorcista que se extenderán en términos generales a "exorcistas judíos” en Qumrán. La oración de Noé (Jub 10, 1-3-7) está marcada por dos motivos. Reconocimiento de la misericordia de Dios con Noé y petición de protección para "los hijos de los justos" en contra de los "malos espíritus" (vv.3.5-). En relación a Abram, Ruiten no analiza el texto de Jub 11, 16-24; 48, 12-18, donde se describen las figuras de Abram y Moisés combatiendo a Mastema. Abram narra a sus hijos el castigo de los gigantes y el de Sodoma $(20,5)$. En el texto de Jub 11, 11 sirve de introducción a los vv. 16-24 que señala "el príncipe Mastema envío cuervos y aves a comerse la semilla que se plantaba sobre la tierra...". Los vv. 16-23 resaltan la figura de Abram y muestra el poder exorcista de este que funciona como contratipo al relato del mito de los Vigilantes "aquel día se volvieron setenta nubes de cuervos, no quedando ni uno en todos los campos donde estuvo Abram”. Así como Abram, Moisés intercede ante el Señor "Álcese Señor, tu misericordia sobre tu pueblo y créales un espíritu recto, no los rija el espíritu de Beliar" (Jub 1, 20). En Jub 48, 2.3, reinterpreta el texto masorético de Ex 4, 24 atribuyendo a Mastema la acción de asesinar a Moisés "no quiso matarte con toda su fuerza y salvar a los egipcios de su mano...?” Mastema ayudaba con encantamientos y maldad. Por el contrario, Dios, impide que haga "medicinas con sus manos" (v.1); cuando habla de la figura de Noé, Dios comunica al patriarca "los remedios y enfermedades, juntamente con sus engaños, para que curase las plantas de la tierra" (Jub 9, 12); Dios ordena que Mastema sea "atado y encerrado" (vv.15.18), incluso Mastema "es liberado" para que ayude en la persecución de los israelitas. Las oraciones y bendiciones están enmarcadas en el tema de la salvación y el carácter exorcistas de la vida de los patriarcas. Así como Noé, la oración y bendición de Abram está en relación a la protección contra los demonios "no tengan poder sobre ti ni de tu descendencia los espíritus de Mastema para alejarte del señor, tu Dios" (Jub 1, 20; 4, 3.22; 10, 3-6; $12,20 ; 19,28)$.

\section{Demonología dentro de la historia salvífica}

En el libro de los Jubileos, finales del siglo II, conoce el mito de los Vigilantes $(5,1-4)$; existe una similar concepción de la demonología presente en 1 Enoch y Jubileos. Este último sigue el mito de los Vigilantes 
específicamente con la tradición de Shemyaza (Jub 5, 1-2), en cambio, respecto de los conocimientos médicos y botánicos son valorados positivamente en el sentido que los ángeles "él mandó que debíamos enseñar a Noé medicamentos" (Jub 10, 10); de la misma manera, en Jubileos la demonología aparece agrupada en listas de demonios, y listas de impíos (CD-A V, 18 Jd 1, 11 ); esta cuestión no menor apunta a describir a los demonios e impíos de acuerdo a un reino guiado por un jerarca Mastema o Satán (Jub 10, 11); sin embargo se diferencia de la demonología de 1Enoch en el hecho que contextualiza la demonología de 1 Enoch en relación a la historia salvífica de Israel. En este mismo sentido, el lugar de Enoch como visionario queda reemplazado por la figura de Moisés a quien le es revelado lo que sucederá. En otra parte hemos puesto de relieve la relación existente en 1 Enoch 7, 5 y Gén 9, 4-6 entre el mandato de no derramar sangre y la figura de Abel. La contaminación recae de acuerdo a la idea extendida en la antigüedad no solo sobre la persona sino también sobre la tierra en la cual se derrama la sangre, profanando de esta manera el país; sin embargo la demonología es presentada no como ángeles rebeldes sino como un ejército, o reino estructurado, el cual están en definitiva bajo la voluntad de Yahvéh, en efecto, Mastema ruega ante Yahvéh que deje una décima parte (Jub 10,9). Noé constata que la pervivencia de los demonios como señala Jub 7, 27; 10, 1: "en el tercer jubileo, comenzaron los demonios impuros a seducir a los nietos de Noé, haciéndolos enloquecer y perderse".

En Jub 11, 2 continúa esta tradición: "los hijos de Noé comenzaron a combatirse, hacerse prisioneros, matarse entre hermanos derramar sangre humana sobre la tierra..." con una innegable alusión al mito de los Vigilantes subraya "se fabricaron estatuas de función y adoraba cada uno a sus ídolos metálicos" y "el príncipe Mastema se esforzaba en hacer todo esto y enviaba otros espíritus que habían sido puestos en su mano para cometer toda clase de extravío, pecado e iniquidad: destruir, arruinar y derramar sangre sobre la tierra”.

Pero como señala J. Collins, el relato de los Vigilantes no fue el único paradigma a partir del cual se comprende el mal en el mundo ${ }^{28}$. En Jubileos aparecen dos tradiciones sobre un pecado de origen: el relato de los ángeles caídos en Jub 5, 1-4 y el relato del Yom Quippur fundado en la venta del patriarca José (Jub 34, 18-19). La conexión entre el relato de

28 Cf. Collins, Apocalypticism, 32. 
José y el texto de Lev 16, 1-36 establece una conexión entre expiación y exorcismo. La expiación anual por este pecado contra José en el día del Yom Quippur muestra un carácter apotropaico de la figura del patriarca. C. Carmichael ha hecho notar el origen del ritual del chivo expiatorio en relación a la figura del patriarca José29. En su esfuerzo de insertar el mito de los Vigilantes en la historia salvífica, para el autor del libro de los Jubileos la figura de José no solo se asemeja a la de Abel, sino que dicha tradición explica el origen del rito del Yom Quippur en relación al relato de Gén 37, 31 "degollaron un cabrito del rebaño y tiñeron la túnica con la sangre", paralelo a Lev 16, 15, con lo cual prueba un sentido apotropaico del sufrimiento de José como fundador de un pueblo. De acuerdo a esto, pareciera que el rito expiatorio pose un carácter exorcista o manifiesta una transferencia simbólica. Como podemos ver en el texto de Jub 34, 18-19, se ordena a los israelitas que guarden luto el diez del séptimo mes: "en él expíen por su pecado con un cabrito, el diez del mes séptimo, una vez al año, pues apenaron las entrañas de su padre a causa de su hijo José". Tal sentido expiatorio fundante y liberador del dominio de Mastema se ve confirmado en Jub 46, 1-2 donde se señala la función expiatoria de José como exorcista y liberador en Egipto: "se multiplicaron mucho durante diez septenarios, todos los días que vivió José. No hubo demonio ni ningún mal en todos los días de la vida de José tras la muerte de su padre".

\section{Demonología y escatología}

Al igual que 1 Enoch la figura del diluvio es considerada como imagen del juicio divino en Jubileos; sin embargo ya en el Libro de los Sueños, el paradigma cambia y el eschaton es elaborado a partir de una periodización de la historia. En el libro de 1Enoch, Dios ordena a los ángeles "atar a Asael de manos y pies y lanzarlo a las tinieblas"; también Semyaza "átalos por setenta generaciones" (1Enoch 10,4.11;13, 1; 14, 5; 69, 28). Es notorio cómo a partir de 13, 1; 14, 5 es Enoch quien es el interlocutor de Asael y no los ángeles. También en Jubileos las bendiciones escatológicas integra el "atar a Satán" y la reiterada afirmación: "y allí será ni Satán ni ningún mal destructor” (Jub 10, 5-7; 23, 29; 50, 5); y

29 C. Carmichael, "The origin of the Scapegoat ritual", Vetus Testamentum L/2(2000), 167-182; el impacto de esta tradición en el TestXIIPatriarcas: TestRubén 1, 2; TestSimeon 1, 5; TestSimeon 2, 13-14; TestZabulón 1, 5; TestZabulón 5, 4; TestDan 1, 7; TestGad 2, 2. 
lo mismo encontramos con la idea de atar al fuerte" que repite TestLevi 18,1 y Mc 3, 22.

\section{El Último Ciclo de ENOCh y Qumrán}

\section{Epístola de Enoch}

La cita de 1Enoch 101, 4-9 en el texto de 1QHa col. XIV, 22: "yo he llegado a ser como un marino en medio del mar tempestuoso", demuestra la dependencia de este texto de los Hoyadot y de la Epistola de Enoch. La imagen responde a la del sabio que es comparado con el marino sobreviviente de la tempestad que puede contar lo que ha vivido (col. XI, 14; col. XIV, 22). La Epistola de Enoch subraya el carácter histórico del pecado en diversos pasajes p.e. 1Enoch 98, 4 "tampoco el pecado fue enviado a la tierra sino que los hombres lo crearon de sí y gran maldición tendrán los que lo hicieron". Lo cual se asemeja al pensamiento de Sirácida 21, 27 "cuando el impío maldice a Satán él se está maldiciendo a sí mismo". Aunque conoce el mito de los Vigilantes $(91,13)$, no se refiere a este para explicar el pecado en el mundo. En esto debe verse una reacción al determinismo del mito de los Vigilantes para el cual la historia está ya corrompida.

En el capítulo 93, 1-17 se encuentra el Apocalipsis de las diez semanas a juicio de $S$. Reid, como el "más antiguo apocalipsis judío" ${ }^{30}$. La historia aparece dividida en diez semanas y refleja un degenerativo concepto de la historia lo que expresa a juicio de P. Sacchi que la Epistola de Enoch deriva del Libro de los Sueños y de Daniel ${ }^{31}$. La figura de los justos que son desarrollados sociológicamente muestra una nueva conciencia de la libertad y responsabilidad humana ante su destino. (2 Pd 2, 4; Jud 1, 6). En la Epístola se encuentra desarrollado el concepto de justo ya mencionado en el Libro de los Vigilantes (1 Enoch 5, 7; 10, 17; 25, 4) donde se habla que "este árbol será dado a los justos y humildes". Aunque Sacchi comenta: "Los elegidos son para nuestro autor los justos y los humildes" ${ }^{32}$, este no saca las conclusiones pertinentes y no considera la cita de 1Enoch 2, 7 "los elegidos [...] ellos heredarán la tierra", que

\footnotetext{
30 S.B., ReID, "The Structure of the Ten Week Apocalypse and the Book of Dream Visions”, JSJ XVI (1984)2, 189.

31 Cf. SAcchi, Jewish Apocalyptic and its History, 114

32 SACCHI, "Riflessioni", 49.
} 
interpreta el salmo 37, 11: "los pobres heredarán la tierra". Tampoco es casualidad que durante este periodo aparecen una serie de listas de sujetos marginales y perseguidos, así como en 1En 104, 2 y TestJudá 25,4 , donde se enumera a los justos: pobres, pobres, enfermos necesitados, a quienes se les promete la vida, siguiendo en esto el esquema de humillación-exaltación estudiado por G. Nickelsburg ${ }^{33}$. Esta coincidencia ideológica no es casual y muestra a juicio de Boccaccini un tema teológico: "elegidos (justos y sabios) y los impíos (pecadores y necios) son respectivamente identificados con los pobres (los indefensos) y los ricos (los poderosos)" ${ }^{34}$. Los justos identificados con los pobres en estas listas son sujetos escatológicos que encontramos en Ap.Sof 7, 2-11; Job 31, 13-23; Mt 25, 31-46. El justo no es solo quien protege al huérfano y a la viuda, sino que ahora se trata que el justo se identifica con aquel que padece como lo muestra el Test José 1, 1-7.

2. CD y TestXII Patriarcas. Dos demonologías

El Documento de Damasco es a juicio de Boccaccini un "texto de transición" ${ }^{35}$, así lo muestran los textos de 4Q266 fr. 2 col II, 18 (= CD-A I 21- II 21) que testimonian que en Qumrán conocían el mito de los Vigilantes "los Vigilantes de los cielos cayeron" (4Q532 fr.2 7; 4Q534, 7) ${ }^{36}$. Además, aún conserva la raíz del mal en el deseo de los Vigilantes: "ellos han realizado su deseo". (CD-A col. II, 20), y no en la interioridad de los hombres o en la historia mundana como lo hará la Epistola de Enoch. También en 4Q544 fr. 21 [... yo] domino sobre ti [...] 2 [...] este Vigilante] ¿quién es él? Y él me dijo: "este es llamado...] 3 [...] y Melqui-resha'. El Documento profesa un determinismo radical entre elegidos y justos y los que pertenecen al lote del príncipe de las tinieblas. Sin embargo, a juicio de J.J. Collins en Qumrán "encontramos en Instrucción de los dos espíritus, una nueva síntesis que va más allá que cualquiera otra

33 G. Nickelsburg, Resurrection, Immortality, and Eternal Life in Intertestamental Judaism and Early Christianity, Expanded Edition (New Haeven 2006) 278.

34 Boccaccini, Oltre l'ipotesi essenica, 243.

35 Boccaccini, Oltre l'ipotesi essenica, 215.

36 Los lugares en que aparece menciona el mito de los Vigilantes en Qumrán son: CD-A II, col. II, 18(4Q266) fr. 3 col. I, 18; 1QapGen ar col.II, 1; col. IV, 16; col. VI, 13; col.VII, 2; 4Q201 4QEnoch ${ }^{\mathrm{a}}$ ar col.I, 3; col.V, 5; 4Q202 4QEnoch ${ }^{\mathrm{b}}$ ar col. II, 3; col. II-2- col. III, 15; 4Q204 col. V, 3; col. VI, 8.9-12; 4Q206 4QEnoch ar fr. 2 col.II, 5; 4Q227 fr.2, 1. 
de sus precedentes judíos" ${ }^{37}$. A juicio de Collins en CD no está entendido el mito de los Vigilantes como el "origen y fuente de la pecaminosidad humana" ${ }^{38}$. Collins sostiene que la fuente yace más bien en la inclinación del corazón humano (1Q26, 4Q415-18, 423). Pero esta posición no se ve bien cómo se conjuga con el texto de CD-A col. III, 21-col. IV, 19. Pensamos más bien que CD profesa la perspectiva histórica ya desarrollada en textos como el Libro de los Sueños y Jubileos. CD inserta el mito de los Vigilantes dentro del ciclo de los patriarcas de manera similar a como lo hizo Jubileos, además, integrando la mediación histórica de la Escritura, introduce, la interpretación escatológica pesher, incluyendo textos de la Escritura como portadores de misterios. Es significativo que CD-A col. III, 21-col. IV, 19, cita el TestLeví 16-17, que menciona que el juicio comienza con el envío del ángel Belial, en los vv. 12-13, e introduce la cita de Is 24, 17:

"Y durante todos esos años Belial será enviado contra Israel, como ha dicho por medio de Isaías el profeta hijo de Amós diciendo: (Is 24, 17) pánico, fosa, red contra ti, habitante de la tierra”.

Este texto pertenece al Apocalipsis de Isaías 24-27, el cual es interpretado por el escritor inspirado mediante el texto del Testamento de Leví, lo cual prueba su origen pre-qumrámico. El redactor de CD identifica históricamente esta cita con los vicios y males que sufren sus contemporáneos, signos del envío de Belial a la tierra, y de la llegada de los últimos tiempos, época de dolores y de persecución para los justos, antes de la llegada del eschaton. Además, encontramos en la segunda etapa de los escritos de Qumrán ${ }^{39}$, textos como 11QMelq que interpreta el Salmo 82, 2 mencionando a Belial en dos ocasiones vv. 12.13 "su interpretación concierne a Belial y a los espíritus de su lote". Esto muestra que CD y otros escritos propios de Qumrán mantienen la idea de la pecaminosidad humana dependiente del pecado de los ángeles caídos.

\section{Dualismo y determinismo}

Pareciera ser que la demonología en Qumrán no es un sistema homogéneo, y más bien pensamos que coexisten diversos sistemas demonológicos en tensión. Una gran cantidad de autores estiman que la demo-

37 Collins, Apocalypticism, 35.

38 Collins, Apocalypticism, 36.

39 Cf. García Martínez, Literatura Judía, 85. 
nología de Qumrán es dualista estructurada en dos lotes: una, guiada por el príncipe de la luz; otra, liderada por el ángel de las tinieblas (1QS col. III, 20). De manera similar a Jubileos, se trata no de un dualismo absoluto sino parcial, así se muestra en 1QS col. III, 25 señala que "el creó los espíritus de la luz y de las tinieblas y sobre ellos estableció todos los hechos". En cambio, otros textos, muestran otros acentos como p.e. 1QS col.III, 17, en donde dice que Dios ha creado el hombre "para que domine la tierra y ubicó dentro de él dos espíritus".

En algunos pasajes se menciona que el tiempo presente está dominado por el príncipe de las tinieblas. Este tiempo es el "dominio de la injusticia", "el dominio de la impiedad" (1QS col. IV, 19-20; 4Q510, 6; 1QM col. XVIII, 5-6). Sin embargo, es un tiempo acotado, Dios "puso un tiempo a la existencia de la injusticia" (1QS col. IV, 18). Diversos pasajes de Qumrán nos entregan importantes datos sobre el estado de injusticia de la creación y la situación de persecución y hostilidad que sufre la comunidad. Investigadores como J. Collins sostienen que existe un corpus de escritos que expresan "un dualismo de los dos espíritus" entendidos como inclinación al mal fuente de la pecaminosidad humana, p.e. el texto de $1 Q S 3,15-19$, el cual en principio es similar con la demonología del TestRubén 2, 2.8 ya que derivan el pecado del espíritus que están en el interior del hombre; no obstante que en 1QS, a diferencia del Testamento de Rubén no se habla de un espíritu sino de múltiples espíritus dentro de cada ser humano.

\section{La impureza y los justos y la gloria de Adán}

Dios ha creado dos lotes, los hijos de la justicia y de la injusticia. Los hijos de la justicia están bajo la protección del príncipe de la luz "el príncipe de la luz tiene dominio sobre todos los hijos de la justicia" (1QS col. IV, 20). Como ha sido estudiado por C. Flechter, y J. Sharpe ${ }^{40}$, Dios ha creado a Adán de manera semejante a los ángeles, ya en el Libro de los Sueños es descrito como un toro blanco $(1$ Enoch 85,3$)$ símbolo de los justos. Según Collins "los textos sapienciales de Qumrán comprenden a la humanidad divida en dos tipos de humanidad desde un comienzo ${ }^{41}$ :

40 H.T. FLETCHER-Louis, All the glory of Adam: Liturgical Anthropology in the Dead Sea Scrolls, (Brill, Koln, 2002), 122; J. L. Sharpe, "The second Adam in the Apocalypse of Mose", CBQ XXV (1973) 35-46.

41 Collins, Apocalypticism, 39. 
"un pueblo espiritual" a semejanza de los ángeles y otro "espíritu de carne". Por esto que a los justos, a los miembros de la secta pertenece la gloria de Adán (1QS col. IV, 23) y sus nombres están escritos. Esta idea también está desarrollada en textos contemporáneos como en el Libro de las Parábolas (1Enoch 69, 10) "no fueron creados los hombres sino como los ángeles, santos y justos y la muerte que todo lo destruye, no los habría alcanzado, pero debido a este conocimiento eran destruidos". Desde un comienzo están predestinados los hijos de la luz a brillar como estrellas: "los hijos de la justicia brillarán eternamente [...] y tendrán gloria y alegría". Y lo mismo aparece en Apocalipsis de Moisés 20-21 con una distinta demonología comparable a la que subsiste en Sab 2, 24 y Vida de Adán y Eva 12-16; Enoch Hebreo 4, 5-8, en este sentido tiene razón M. Elliot ${ }^{42}$ y es necesario reconocer la mayor importancia que adquiere la figura de Adán en los escritos de Qumrán por lo que es necesario hablar de una teodicea de Adán.

\section{Teodicea y exorcismos en Qumrán}

En Qumrán encontramos desarrollada la pregunta por la teodicea como ocultamiento del rostro de Yahvéh en los últimos días p.e. en Catena 4Q177 col. II, 8 encontramos citado el Sal 13, 1-2:

“¿Hasta cuándo, Yahvéh? ¿Me olvidarás para siempre? ¿Hasta cuándo esconderás tu rostro de mí? [...] La interpretación de la palabra concierne a la purificación del corazón de los hombres de la comunidad."

La interpretación del salmo no solo ha sido escatologizada sino que representa una solución al problema de la injusticia entendida como contaminación e impureza; el tiempo malo de los últimos días es comprendido como purificación del corazón. No es casual que Martin Hengel comente que "angelología también forma el trasfondo de la demonología esenia y sus exorcismos. Los demonios son relacionados con los ángeles caídos. Probablemente el don esenio de sanar acentuado por Josefo tiene un trasfondo exorcista ${ }^{43}$. Ciertamente, los exorcismos en Qumrán debemos considerarlos dentro del ámbito de la demonología y actividad exorcista de los patriarcas semejante a como lo encontramos

42 M. ElLiot, "Origins and functions of the Wachters theodicy", Henoch vol. XXIV (202), 63.

43 M. Hengel "Qumran and helenismus", en J.J. Collins and R. Kugler(eds.)Religion in the Dead Sea Scrolls (Grand Rapids, Michigan 2000) 53. 
en Jubileos. Ángeles, patriarcas, profetas colaboran mediante los exorcismos en la lucha contra los demonios. El texto de 4Q197 4QTobit ar presenta en este relato al ángel Rafael que acompaña a Tobit para pescar un pez. Como argumenta Brandon, en la antigüedad se usan diversos animales, objetos, acciones y conjuros que se creía tener un efecto protector o exorcista ${ }^{44}$; así, el ángel manda a Tobit extraer el corazón, el hígado y las agallas, fr.4 col I "Dividir y quitar su agalla, su corazón 9 y su hígado, y mantenerlos en la mano, pero deshacerse de sus entrañas, por su agalla, su corazón y su hígado son una buena medicina" los cuales poseen un efecto apotropaico para expulsar al demonio que está en Sara, hija de Raguel. Sara ya ha tenido siete esposos y todos han muerto a causa del demonio que no deja acercarse (fr.4, 9). El mismo ángel explica el efecto de dicha acción: "le dijo: 'Si tu humo está ante un hombre o una mujer atacada por un demonio o un espíritu maligno [huirá de ellos]"”.

Bendiciones, fórmulas de encantamiento y oraciones tiene un carácter exorcista, a juicio de Mach "la oración es uno de los medios por los cuales se protege contra estos demonios" ${ }^{45}$. El fr. 1 col. II presenta una fórmula de encantamiento "oh yo espíritu te conjuro, oh espíritu yo te encanto...". De la misma manera que 11Q11 menciona una fórmula de encantamiento de espíritus y demonios. La oración de Nabodias en 4Q242 sostiene que el rey tiene "una inflamación maligna decretada por el Dios altísimo" a causa de un pecado de idolatría: "yo había orado por siete años a todos los dioses de plata y oro de bronce y hierro de madera y piedra y de arcilla porque yo pensaba que eran dioses". Un exorcista judío perdona su pecado mandándole realizar un escrito dando honor y gloria a Yahvéh. En otro texto, 4Q560 4QExorcism ar, fr. 1 col. 1 describe un demonio llamado "el castigador de las niñas" y continúa en el v.2 el "mal visitador" que provoca "fiebre, escalofríos, el calor del corazón". Es importante anotar que dicho texto muestra la misma diferencia entre síntoma y causa, enfermedad y demonio como TestSalomón 18, 1-41, pero que en otros textos se identifican, como es el caso del Libro de las Parábolas (1Enoch 69, 3-13). En los textos de 4Q511-512 y 11Q6, en este último texto, dice: "que Satán no domine sobre mí, ni un mal es-

44 Cf. S.G. F. Brandon, Diccionario de religiones comparadas (Paidós, Madrid 1975) 416.

45 Mach, Demons, 191. 
píritu tampoco, ni mal objetivo tome posesión de mis huesos" ${ }^{46}$. El uso de conjuros y oraciones exorcistas muestra que esta demonología no solo pretende explicar la causa de una mala disposición o el origen de la injusticia en el hombre sino que además pretendía realizar una acción soteriológica en los dolientes y afectados con diversas patologías físicas y mentales, así p.e. 4Q560; 4Q Exorcism ar fr.1 col. I "iniquidad y culpa; fiebre y escalofrío, subida de presión 5 [...] en sueño" muestra la idea que patologías físicas como fiebre, dolores estomacales, y enfermedades mentales fueron considerados como manifestación de un demonio o producido por uno de ellos. De la misma manera la descripción de propósitos, deseos, sentimientos, actitudes, etc. Ahora bien, es fundamental atender que esta perspectiva antropológica está plenamente vigente en el siglo I. d.C, y es un presupuesto esencial para comprender diversos textos neotestamentarios.

En el texto de 11Q11 col. II1 v. 2 encontramos el nombre de Solomón el cual tenía fama de exorcista, posteriormente afirma el texto "y el invocará" en el vv. 3-4 [... los espíritus y los demonios [...] 4 [...] éstos son los demonios y el príncipe de animosidad". Por estos datos, es muy posible que 11Q11 sea un texto de exorcismo semejante al que encontramos en el TestJob 27, 1-7 o TestSalomón, 6, 11 donde el núcleo del exorcismo a juicio de É. Puech radica en la invocación en el nombre de

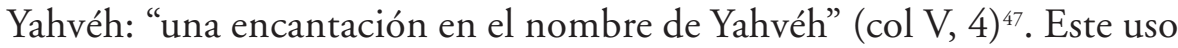
del nombre inefable representa ya un poder mágico contra los demonios en las Parábolas de Enoch (1Enoch 69, 14-25). Más aún, si mencionamos el uso del Salmo 91 que se emplea más adelante, vemos un uso apotropaico del Salmo en contra de los hijos de Belial mencionado en el v. 3; este uso comprende una oración de exorcismo contra los demonios de la pestilencia y la plaga mencionados en los vv.5.7.10 así como de los animales mencionados en los vv. 12. 13 "sobre serpiente y áspides tu paso, tú caminarás entre leones y dragones”.

46 Cf. 4Q560 [4QExorcism ar].

47 Cf. É. Puech, . "Los manuscritos del Mar Muerto y el Nuevo Testamento. El nuevo Moisés: algunas prácticas de la ley”. Antiguo Oriente: Cuadernos del Centro de Estudios de Historia del Antiguo Oriente 7 (2009). http://bibliotecadigital.uca. edu.ar/repositorio/revistas/manuscritos-mar-muertonuevo-testamento.pdf [consulta 26 de Enero, 2016]. 
6. El tiempo escatológico y lucha contra demonios

A diferencia de los justos presentes en el salterio, que exclusivamente padecen la injusticia de los impíos, encontramos otros textos apocalípticos ya mencionados como Jubileos en donde patriarcas, o como en 11Q11 col. II1 v. 2, figuras como Solomón son exorcistas que colaboran en la lucha contra los demonios: "él invocará" en el vv. 3-4 [... los espíritus y los demonios [...] 4 [...] estos son los demonios y el príncipe de animosidad". En textos posteriores como en el TestJob 27, 1-7 muestra a Job como un "atleta" que lucha contra Satán, y el TestSalomón, 6, 11 donde el exorcista manda callar a los demonios; son muestra que los justos no solo padecen sino que luchan y colaboran como los ángeles contra los demonios.

Ciertamente un cambio significativo radica en la diversa escatología que representa Qumrán referido a la impureza y justificación. Si ya el judaísmo enóquico había desarrollado una ruptura con el esquema sacrificial jerosolimitano, el judaísmo esenio se distingue incluso de otros textos del movimiento enóquico por el hecho de considerar que Dios por su justicia, purifica y hace justo al hombre como un bien presente y no solo remitido a un futuro día del juicio: "porque tú purificas la iniquidad y limpias al hombre de su culpa por tu justicia" (1QHa col. $\mathrm{XI}, 37)$. A nuestro parecer este es un cambio radical solo comparable a la introducción del mito de los Vigilantes y quizás haya que ver antecedentes de esta justificación, en la figura del rapto de Enoch al cielo y en los sucesivos raptos de héroes judíos (1Enoch 12, 1; Enoch Hebreo 4, 5-8). En este texto, la justificación es identificada con un don presente en medio de la comunidad e identifica la expiación y como un acto de purificación escatológica: "El día de la expiación es el fin del décimo jubileo" como lo encontramos en 11QMelq. Melquisedec declara el décimo jubileo en el día del Yom Quippur de acuerdo al texto de Is 61, 1-2. Al parecer en este aspecto escatológico de la justicia que se aprecia en la neumatología de la secta, por la que el hombre recupera la gloria de Adán, no se aprecia ningún papel para un mesías, ni para otras instituciones religiosas judías, ni por la purificación de aguas, ni santificado por el mar o los ríos, sino por el espíritu santo (1QS col III, 1-11); "pero Dios... purificó sus iniquidades y perdonó sus pecados... ellos adquirirán eterna vida y toda la gloria de Adán es para ellos" (CDA col. III, 18-20). 


\section{CONCLUSIONES}

Los diferentes cambios producidos en la demonología judía y su inserción en el curso histórico, nos muestra que el núcleo central radica en la convicción de un estado de injusticia en que ha caído la humanidad a raíz del pecado de los ángeles, reiterado en diversos documentos de esta época. Posterior al Libro de los Vigilantes, la demonología míticotrascendental es contextualizada en el marco de la historia humana de acuerdo a un uso de pasajes de la escritura y de una periodización que integra la historia de la salvación de Israel mediante diversos argumentos. Es comprensible que en este horizonte, el tema de la pregunta por el sentido del sufrimiento haya sido relacionado con la presencia de exorcismos, y acciones como bendiciones, oraciones y ritos apotropaicos que poseen un carácter soteriológico y no tan solo medicinal como acontece en contextos culturales vecinos a Israel. No es casual entonces que la demonología, en el contexto del proceso de escatologización que se produce en grupos apocalípticos se vuelve hacia el problema de la teodicea, lo cual explica que la promesa de la eliminación del mal sea un bien escatológico para el final de los tiempos; en Qumrán encontramos la convicción de la justificación actual como regalo divino que obliga a pensar en una teodicea centrada en la figura de Adán. La cuestión de la liberación del poder de los demonios y de la justicia divina por tanto lleva a describir dos aspectos: primero, la identificación entre contaminación y pecado conlleva una superación del esquema sacrificial judío y abre las posibilidades para ulteriores desarrollos en la comprensión de la salvación de los elegidos. La pervivencia del mal en la historia pretende responder a la condición pecaminosa que subsiste en la historia y que conlleva una agonía para el creyente; segundo, la reflexión demonológica judía durante el judaísmo tardío pretende responder a la cuestión del mal en la historia, por lo que ha querido enmarcar la creencia en demonios dentro de la historia de salvación, colocando a Moisés como revelador y a los patriarcas y profetas como exorcistas; la escatologización de la demonología conlleva una superación del mal desarrollando un determinismo histórico el cual conlleva finalmente el anuncio del triunfo de Dios sobre los demonios, atando a Belial en el juicio de Dios. 
